XX Міжнародний симпозіум «Методи дискретних особливостей в задачах математичної фізики/Discrete Singularities Methods in Mathematical Physics», МДОЗМФ/DSMMPh-2021

УДК 627.41 .8

MSC 34B60

\title{
Physical and mathematical modeling of the wave quenching chamber with the upper part in the form of a permeable waterfront
}

\author{
L.M. Tereshchenko, V.V. Khomicky, V.O. Tkachenko, I.A. Nikitin, \\ A.G. Kharchenko, L.P. Abramova, I.A. Khiza, I.B. Kudybyn \\ Institute of Hydromechanics Academy of Sciences of Ukraine, Kyiv, Ukraine \\ E-mail: litere70@gmail.com, homicky@ukr.net, tkachenkob@gmail.com, \\ nia37@ukr.net, Anatoliy.kharchenko62@gmail.com,luda54@ukr.net, \\ fholinder@gmail.com,igorkud33@gmail.com
}

This paper presents the results of mathematical and physical modeling of the interaction of waves with the wave chamber on cylindrical supports and the upper part in the form of a permeable waterfront. On the basis of the diffraction model the mathematical modeling of refraction and transformation of waves near the structure is carried out. In the presence of a structure, the transformation of waves is co-accompanied by the phenomena of wave destruction at the edges of the structure and the partial reflection of residual waves from the walls of the protective front. Reflection phenomena cause changes in wave heights along the front of the structure. The results of experimental data are given, which showed that the structure with such a construction is resistant to waves, large soil erosion was not observed.

Key words: wave quenching chamber, physical modeling, coastal protection, permeable waterfront, wave diffraction.

\section{Фізичне та математичне моделювання хвилегасячої камери 3 верхньою частиною у вигляді проникної набережної}

\author{
Л.М. Терещенко, В.В. Хомицький, В.О. Ткаченко, І.А. Нікітін, \\ А.Г. Харченко, Л.П. Абрамова, І.А. Хижа, І.Б. Кудибин \\ Інститут гідромеханіки НАН України, Київ, Україна \\ E-mail:litere70@gmail.com,homicky@ukr.net, tkachenkob@gmail.com, \\ nia37@ukr.net, Anatoliy.kharchenko62@gmail.com,luda54@ukr.net, \\ fholinder@gmail.com,igorkud33@gmail.com
}

В даній роботі представлені результати математичного та фізичного моделювання взаємодії хвиль із хвилегасною камерою на циліндричних опорах та верхньою частиною у вигляді проникної набережної. На основі дифракційної моделі проведено математичне моделювання рефракції та трансформації хвиль біля споруди. При наявності споруди трансформація хвиль супроводжується явищами руйнування хвиль на краях споруди і частковим відбиттям залишкових хвиль від стінок захисного фронту. Явища відбиття викликають зміни висот хвиль уздовж фронту споруди. Приведено результати експериментальних даних, які показали, що споруда при такій конструкції стійка до дії хвиль, великих розмивів грунту не спостерігалось.

Ключові слова: хвилегасна камера, фізичне моделювання, захист берегів, проникна набережна, дифракція хвиль.

() Терещенко Л.М., Хомицький В.В., Ткаченко В.О., Нікітін І.А., Харченко А.Г., Абрамова Л.П., Хижа І.А., Кудибин І.Б., 2021 


\section{1. Вступ}

В зв'язку з кліматичними змінами рівень світового океану збільшився, що призвело до природних катаклізмів, а діяльність людини до екологічних проблем. Великі шторми розмивають береги та паводки затоплюють, знищуючи всю інфраструктуру прибережної зони хвилею. На границі вода суша неперервно проходять процеси розмиву, переміщення та акумуляції наносів, які в природних умовах приводять до природнього перерозподілу твердої речовини. Інженерна діяльність в береговій зоні змінює береги та напрямок руху наносів, приводить до руйнування природної рівноваги та деформації берега, темпи якої перевищують природні Тому дуже актуальним $\epsilon$ не тільки розробка та удосконалення методів захисту берегової лінії, але й поліпшення екологічної ситуація в районі захисту. Основними цілями сучасного берегозахисту є вивчення та вибір найбільш оптимальних прибережних захисних споруд з економічної та екологічної точок зору. Фізичне та математичне моделювання впливу явищ та процесів на берегову лінію дає чіткі відповіді щодо вибору найбільш ефективної конструкції в умовах глобальних змін клімату. Використання проникних берегозахисних споруд поліпшує екологію прибережної зони та дозволяє зменшити витрати на будівництво. На відміну від суцільних непроникних споруд такі конструкції дозволяють зменшити застійні області, де на водній поверхні збирається сміття, поліпшують умови нересту і переміщення морських тварин [1-5].

\section{2. Експериментальна модель.}

Для експериментальних досліджень використовувалась модель хвилегасної камери із пальових ростверків нижнього рівня (відмітка покрівлі 1,20 м) на циліндричних опорах діаметром 0,6 м. Верхня частина камери-проникна набережна 3 циліндричних оболонок діаметром 0,3 м і проникністю $\mathrm{n}=0,5$. Відмітка покрівлі 5,40м. Основа камери від передньої опори нижнього рівня до стику зі стінкою споруди прикрита кам'янонакидним укісним кріпленням 3 різнорідного матеріалу 3 розміром каменю захисного шару 1 ... 1,5 м. Камера спирається на підготовлену основу з відсипкою щебеневого фільтра і примикає з боку води до підводного банкету-берми шириною 15 м 3 відміткою верху -3,0 м. Упорний пояс банкету виконаний із тетраподів марки Т-13. Берма виконана з каменю $1 \ldots 1,5$ м. Розклинювання кам'яної накидки та заповнення пустот здійснюється з різнорідної гірської маси.

Загальний вигляд моделі показаний на рис. 1. Модельні характеристики споруди визначені відповідним перерахунком розмірів відповідно до прийнятого масштабом. Крупність каменю захисного шару берми і укісного кріплення змінювався від 2,5 ... 3,75 см. Для розклинювания кам'яної накидки і заповнення пустот використовувався несортований щебінь $0,7 \ldots 1,5$ см. В упорному поясі використовувалися модельні зразки тетраподів Т-13. Визначались можливі хвильові навантаження на окремі вузли конструкції берегоукріплювальної споруди. Масштаб моделі берегової ділянки зі спорудами дозволяє в геометрично подібних системах (натура- модель) отримати геометричні характеристики хвильового потоку і споруд шляхом перерахунку через відповідні масштабні коефіцієнти: лінійні розміри - $\mathrm{k}$ $=40$; об'ємні величини - $\mathrm{k}=40^{3}=64000$; час та швидкість $-\mathrm{k}=\sqrt{40}=6,35$; маса та сила $-\mathrm{k}=40^{3}=64000$. Виходячи 3 технічних можливостей експериментальних устано- 
XX Міжнародний симпозіум «Методи дискретних особливостей в задачах математичної фізики/Discrete Singularities Methods in Mathematical Physics»,

\section{МДОЗМФ/DSMMPh-2021}

вок і розмірів хвильового басейну, масштаб моделі був прийнятий рівним $n_{B}=n_{\Gamma}=1: 40$ ( $n_{B}, n_{\Gamma}$ - вертикальний та горизонтальний масштаб моделі). При обраних масштабах на моделях забезпечувалися умови автомодельности по числу Рейнольдса $[6,7]$. Для перевірки даної конструкції до дії хвиль проводилось багато експериментів та математичних розрахунків, але в даній роботі наводяться тільки деякі результати математичного та фізичного моделювання.

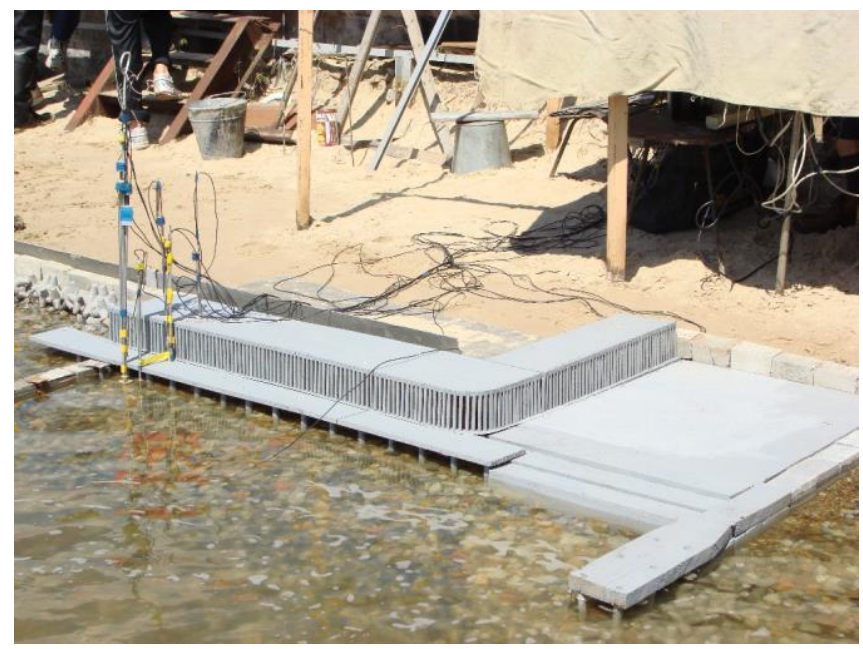

Рис.1 Загальний вигляд моделі

\section{3. Математичне моделювання}

При математичному моделюванні розглядалась задача рефракції гармонійних хвиль, що приходять 3 глибокої води в мілководну прибережну зону, яка характеризується змінною глибиною. Для розв'язку задачі використовувались основі рівнянь теорії хвиль 3 спрощеним підходом, що базується на променевому методі. Рівняння променевого методу базуються на принципі Ферма, згідно з яким промінь поширення хвиль, що задається параметрично у вигляді $x=x(t), y=y(t)$, проходить шлях за мінімальний час і задовольняє рівнянням [8]

$$
\frac{d x}{d t}=c \cos \alpha, \frac{d y}{d t}=c \sin \alpha, \frac{d \alpha}{d t}=\frac{\partial c}{\partial x} \sin \alpha-\frac{\partial c}{\partial y} \cos \alpha,
$$

де $t$ - час проходження променя, $\alpha$ - кут між променем та віссю $x, c(x, y)=\lambda . / T-$ швидкість поширення хвилі, $\lambda(x, y)$ - довжина хвилі, $T=\sqrt{2 \pi \lambda /(g \operatorname{th}(2 \pi d / \lambda))}$, період хвилі, $d(x, y)$ - глибина.

Коефіцієнт рефракції визначається за формулою[8]

$$
K_{\mathrm{p}}=1 / \sqrt{\beta},
$$

де $\beta=l / l_{u c x}$ - коефіцієнт поділу променів, $l_{u c x}$ - відстань між променями на глибокій воді.

Коефіцієнт поділу променів $\beta$ задовольняє рівнянню [8]

$$
\frac{d^{2} \beta}{d t^{2}}+P(t) \frac{d \beta}{d t}+Q(t) \beta=0 .
$$


L.M. Tereshchenko, V.V. Khomicky, V.O. Tkachenko, I.A. Nikitin, A.G. Kharchenko, L.P. Abramova,

\section{I.A. Khiza, I.B. Kudybyn}

Тут величини $P(t)$ и $Q(t)$, визначаємо за формулами

$$
P=-2\left(\frac{\partial c}{\partial x} \cos \alpha+\frac{\partial c}{\partial y} \sin \alpha\right), \quad Q=c\left(\frac{\partial^{2} c}{\partial x^{2}} \sin ^{2} \alpha-\frac{\partial^{2} c}{\partial x \partial y} \sin 2 \alpha+\frac{\partial^{2} c}{\partial y^{2}}\right) .
$$

Введенням допоміжної змінної $\frac{d \beta}{d t}=\delta$ рівняння (3) наводиться до системи рівнянь першого порядку

$$
\frac{\partial \beta}{\partial t}=\delta, \quad \frac{\partial \delta}{\partial t}=-P(t) \delta-Q(t) \beta
$$

На рис. 2 показана променева картина і параметри хвиль, що набігають уздовж променя хвиль при Сх та СхПдСх напрямках вітру
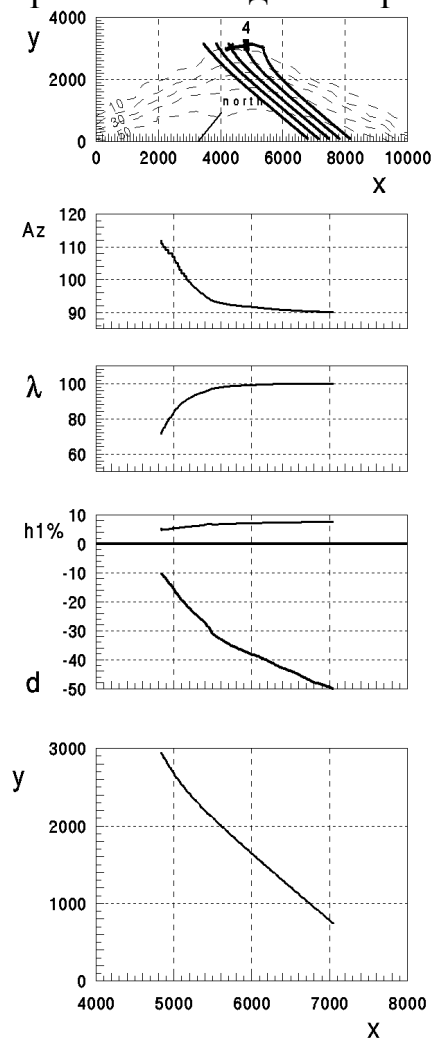

a)

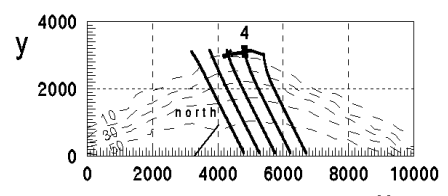

$\mathrm{X}$

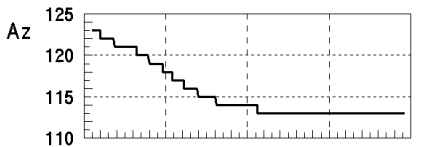

$\lambda 100$
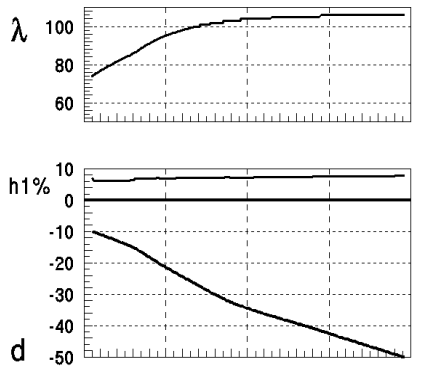

$\mathrm{X}$

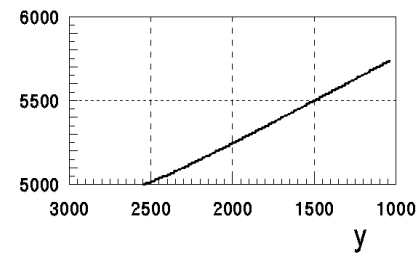

б)

Рис.2. Променева картина і параметри хвиль, що набігають уздовж променя хвиль при Сх (а) та СхПдСх (б) напрямках вітру

Суцільна товста лінія показує променеву картину трансформації хвиль від напрямків розгону вітру Сх та СхПдСх, пунктирні тонкі - ізолінії глибини моря.

На цих малюнках також наведені зміна параметрів набігаючої хвилі вздовж променя, який підходить до досліджуваної ділянки берега. Тут $x, y$ - координати точки

на промені в метрах, $d$ - глибина в цій точці в метрах, $h_{1 \%}, \bar{\lambda}$ та $A_{z}$ - висота, середня довжина в метрах і азимут променя хвилі в цій точці в градусах. 3 проведених 
XX Міжнародний симпозіум «Методи дискретних особливостей в задачах математичної фізики/Discrete Singularities Methods in Mathematical Physics»,

\section{МДОЗМФ/DSMМРh-2021}

чисельних розрахунків видно, що при всіх досліджуваних напрямках дії вітру обвалення хвиль до 10 метрової ізобати не спостерігається.

\section{3. Фізичне моделювання}

Для фізичного моделювання використовувались результати математичного моделювання при забезпеченості розрахункового шторму $2 \%$, осереднені значения параметрів хвиль $(\mathrm{p}=1 \%)$ на підході до споруди від хвиленебезпечного напрямку рівні: СхПдСх - $\mathrm{h}_{1 \%}=6,91 \mathrm{м} ; \bar{\lambda}=77 \mathrm{м} ; \bar{\tau}=7,0 \mathrm{c}$ (ізобата $-10 \mathrm{м}$ ); $\mathrm{h}_{1 \%}=5,08 \mathrm{м} ; \bar{\lambda}=60,9 \mathrm{м}$; $\bar{\tau}=6,23 \mathrm{c}$ (ізобата $-6,5 \mathrm{~m}) ; \theta_{\text {кр }}=0^{0} .3$ урахуванням масштабу моделювання параметри хвиль на моделі були: СхПдСх - $\mathrm{h}_{\mathrm{M}}=0,17 \mathrm{м} ; \bar{\lambda}_{\mathrm{M}}=1,92 \mathrm{м} ; \bar{\tau}_{\mathrm{m}}=1,1 \mathrm{c}$ ( дослід 1) и $\mathrm{h}_{\mathrm{M}}=0,13 \mathrm{м} ; \bar{\lambda}_{\mathrm{M}}=1,52 \mathrm{м} ; \bar{\tau}_{\mathrm{M}}=0,99 \mathrm{c}$ ( дослід 2). Дослід 3 був наступним: СхПдСх $\mathrm{h}_{\mathrm{M}}=0,083 \mathrm{M} ; \bar{\lambda}_{\mathrm{m}}=2,42 \mathrm{~m} ; \bar{\tau}_{\mathrm{s}}=1,61 \mathrm{c}$ чи в натурі $\mathrm{h}_{1 \%}=3,32 \mathrm{м} ; \bar{\lambda}=97 \mathrm{~m} ; \bar{\tau}=10,2 \mathrm{c}$. В дослідах $\mathrm{h}_{1 \%,} \bar{\lambda}, \bar{\tau}$ відповідно осереднені значення висоти, довжини та періоду хвилі. Досліди проводилися при незмінному наповненні басейну $(0,85$ м). Відносна глибина в дослідах змінювалася в межах $H / \lambda$. На рис. 3 показано вигляд моделі під час дослідів.
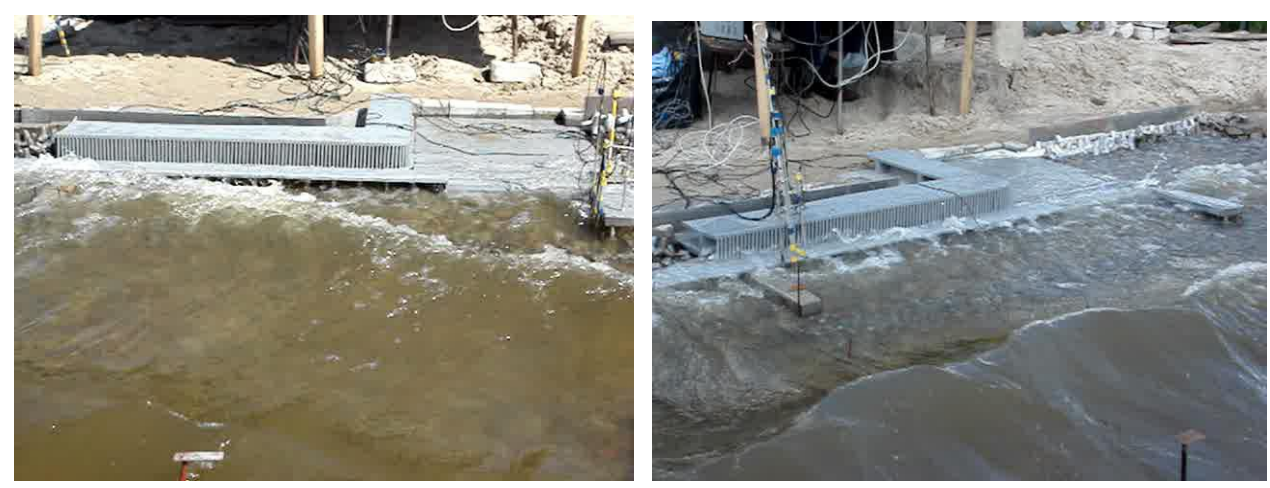

Рис. 3 Вигляд моделі під час дослідів

Підхід хвиль від СхПдСх характеризувався найбільшим розкриттям біля входу в огороджену акваторію для проникнення сюди дифрагованих на споруді хвиль в бухту. Найбільші висоти хвиль $(0,8$ - 1,1 м) спостерігалися на вході в акваторію; у стінки молу і біля набережної висоти хвиль не перевищували 0,8 - 0,9 м. Характер взаємодії хвиль із спорудою відповідає прийнятій в [7] області розрахунків укісних споруд на вплив хвиль, що розбиваються; при обраних основних режимах дії хвиль від СхПдСх. Вихідні виміряні значення висот хвиль на підході до споруди в середньому на $2 \ldots 4 \%$ були меншими розрахункових, а параметри хвиль, що розбиваються практично рівні розрахунковим.

\section{4. Висновки}

Результати фізичного та математичного моделювання показують, що при наявності споруди трансформація хвиль супроводжується явищами руйнування хвиль на краях хвилегасячої берми і частковим відбиттям залишкових хвиль від стінок захисного фронту. Явища відбиття і півхвильового резонансу, що виникають, викликають зміни висот хвиль уздовж фронту споруди. Наприклад, на початку берми висоти хвиль на моделі в натурних величинах змінювалися від 3,36 до 4,2 м; біля 
хвилегасячої камери - від 2,88 до 3,1 м, що на 20 ... 30\% більше визначених на підставі чисельних розрахунків. Крім того, висоти через відбиття від вертикальної стінки досягали величин 4 м і більше. Остаточна руйнація хвилі відбувається на бермі і в хвилегасячій камері. Також спостерігалися сплески хвиль і перехід частини зруйнованого потоку через огороджувальну споруду на пляж. Видно, що характер взаємодії хвиль 3 огороджувальною спорудою відповідає прийнятій в області розрахунків на вплив зруйнованої хвилі на споруди вертикального профілю [7]. Використання такої споруди сприяє захисту берега від штормових хвиль та поліпшенню екологічної ситуації в місці використання.

\section{ЛІТЕРАТУРА}

1. Tereshchenko L., Khomicky V., Abramova L., Kudybyn I., Nikitin I., Tereshchenko I. Physical and mathematical modeling of permeable breakwaters. In: Hu Z., Petoukhov S., Dychka I., He M. (eds) Advances in Computer Science for Engineering and Education. ICCSEEA 2018. Advances in Intelligent Systems and Computing, vol 754. Springer, Cham. 2019. P. 3-12.

2. Zhu Shutang Wave damping over a perforated plate with water chambers. Tsinghua Science and Technology. Volume 11, Issue 3, June 2006. P. 332-338.

3. Carevic, Dalibor, Ocvirk, Eva, Prsic, Marko Redutionof Wave load on the perforated seawall defended by the submerged breakwater. Conference: Twelfth International Symposium on Water Management and Hydraulic Engineering, Gdansk, Poland: Gdansk University of Technology Publishers. 2011. P. 74-92.

4. Fang He, Zhenhua Huang Using an oscillating-water-column structure to reduce wave reflection from a vertical wall. Journal of Waterway Port Coastal and Ocean Engineering. 2016. Volume 142, Issue 2, 32 p.

5. Khomicky V.V., Voskoboinick V.A., Kharchenko A.G., Voskoboinyk O.A., Tereshchenko L.M., Voskoboinick A.V., Nikitin I.A. Defense of beach by active coastprotecting structures. Environmental safety and natural resources. 2019. Vol. 32, No 4. P. 60-77.

6. Voskobijnyk A.V., Voskoboinick V.A., Voskoboinyk O.A., Tereshchenko L.M., Khizha I.A. Feature of the vortex and the jet flows around and inside the three-row pile group. Proc. $8^{\text {th }}$ International Conference on Scour and Erosion (ICSE 2016). Oxford, UK. 2016. P. 897-903.

7. SNiP 2.06.04-82. Loads and impacts on hydraulic structures (wave, ice and from ships). M .: Gosstroy USSR. 1983. 38p.

8. Selezov I.T., Sidorchuk V.N., Yakovlev V.V. Transformation of waves in the coastal zone of the shelf. K.: Naukova Dumka, 1983. 208 p.

Надійшла 22.05.2021 
XX Міжнародний симпозіум «Методи дискретних особливостей в задачах математичної фізики/Discrete Singularities Methods in Mathematical Physics»,

$$
\text { МДОЗМФ/DSMМРh-2021 }
$$

\section{Физическое и математическое моделирование волногасящей ка- меры с верхней частью в виде проникающей набережной}

\section{Л. Терещенко, В.В. Хомицкий, В.А. Ткаченко, И.А. Никитин, А. Харченко, Л.П. Абрамова, И. А. Хищная, И.Б. Кудибин \\ Институт гидромеханики НАН Украины, Киев, Украина \\ E-mail: litere70@gmail.com, homicky@ukr.net, tkachenkob@gmail.com, nia37@ukr.net, Anatoliy.kharchenko62@gmail.com,luda54@ukr.net, fholinder@gmail.com, igorkud33@gmail.com}

В данной работе представлены результаты математического и физического моделирования взаимодействия волн с волногасящей камерой на цилиндрических опорах и верхней частью в виде проникающей набережной. На основе дифракционной модели проведено математическое моделирование рефракции и трансформации волн у сооружения. При наличии сооружения трансформация волн сопровождается явлениями разрушения волн на краях сооружения и частичным отражением волн от стенок защитного фронта. Явления отражения вызывают изменения высот волн вдоль фронта сооружения. Приведены результаты экспериментальных данных, которые показали, что сооружение при такой конструкции устойчиво к воздействию волн, больших размывов грунта не наблюдалось.

Ключевые слова: волногасящая камера, физическое моделирование, защита берегов, проницаема набережная, дифракция волн. 